\title{
Aspectos epidemiológicos e anatomopatológicos do hemagiossarcoma em cães: 40 casos $(1965-2012)^{1}$
}

\author{
Mariana M. Flores ${ }^{2}$, Welden Panziera ${ }^{3}$, Glaucia D. Kommers ${ }^{4}$, \\ Luiz Francisco Irigoyen ${ }^{4}$, Claudio S.L. Barros ${ }^{4}$ e Rafael A. Fighera ${ }^{4 *}$
}

\begin{abstract}
Flores M.M., Panziera W., Kommers G.D., Irigoyen L.F., Barros C.S.L. \& Fighera R.A. 2012. [Epidemiological and pathological aspects of hemangiosarcoma in dogs: 40 cases (1965-2012).] Aspectos epidemiológicos e anatomopatológicos do hemangiossarcoma em cães: 40 casos (1965-2012). Pesquisa Veterinária Brasileira 32(12)1319-1328. Departamento de Patologia, Universidade Federal de Santa Maria, Av. Roraima 1000, Santa Maria, RS 97105-900, Brazil. E-mail: anemiaveterinaria@yahoo.com.br

Epidemiological and pathological aspects of hemangiosarcoma in dogs from the Central Region of the State of Rio Grande do Sul, Brazil. Out of the studied cases ( $\mathrm{n}=40)$, aged dogs (72.2\% of the cases) and dogs of German shepherd breed (20\% of the cases) were clearly more frequently affected since in the total population of necropsied dogs in the same period $(n=7,063)$ this age group and breed were comparatively less represented (respectively $14.6 \%$ e $10.1 \%$ of the cases). At necropsy ( $n=40)$ most tumors (92.5\%) occurred as nodules and less frequently as masses (37.5\%), affecting mainly the spleen (62.5\%), lung (60\%), liver (52.5\%), peritoneum (42.5\%), kidney (37.5\%), brain (30\%), pleura (25\%), and heart (22.5\%). Hemoperitoneum $(42.5 \%$ of the cases) and resultant anemia $(22.5 \%$ of the cases) were also observed. On histological examination $(\mathrm{n}=25)$, most hemangiosarcomas $(84 \%)$, were, in general, well differentiated, of low grade (64\%) and possessed a scant stroma (84\%), although frequently $(68 \%)$ focal areas with cells displaying some degree of atypia were seen. Necrosis, hemorrhage, and thrombosis were observed in all cases, however extramedullary hematopoiesis $(28 \%)$ and benign angiomatous proliferation (12\%) were less common findings. In all cases submitted to immunohistochemistry staining $(n=24)$ the tumor cells displayed a finely granular positive staining when using anti-factor von Willebrand. Regarding anatomical classification, $55 \%$ of the hemangiosarcomas were considered as multicentric, $30 \%$ as primary tumors with one or more metastasis and $15 \%$ were solitary tumors. This paper discusses these results an suggests, based on the combination of affected organs, a scheme for setting apart primary hemangiosarcoma with metastasis from multicentric hemangiosarcoma, aiming to uniformize communication between pathologists regarding this tumor.
\end{abstract}

INDEX TERMS: Diseases of dogs, oncology, neoplasms, multicentric tumors, hemangiosarcoma.

RESUMO.- Os aspectos epidemiológicos e anatomopatológicos de casos de hemangiossarcoma em cães da Região Central do RS foram estudados. Dos casos avaliados ( $n=40)$,

\footnotetext{
${ }^{1}$ Recebido em 3 de setembro de 2012.

Aceito para publicação em 9 de outubro de 2012.

${ }^{2}$ Programa de Pós-Graduação em Medicina Veterinária, área de concentração em Patologia Veterinária, Centro de Ciências Rurais (CCR), Universidade Federal de Santa Maria (UFSM), Camobi, Santa Maria, RS 97105900, Brasil.

${ }^{3}$ Curso de Medicina Veterinária, CCR-UFSM, Santa Maria, RS. Bolsista PIBIC/CNPq/UFSM.

${ }^{4}$ Departamento de Patologia, Centro de Ciências da Saúde, UFSM, Av. Roraima 1000, Santa Maria, RS 97105-900. *Autor para correspondência: anemiaveterinaria@yahoo.com.br
}

cães idosos e da raça Pastor Alemão foram nitidamente os mais afetados $(72,2 \%$ e $20 \%$ dos casos, respectivamente), visto que na população total de cães necropsiados nesse mesmo período $(n=7.063)$ essa faixa etária e raça tiveram comparativamente uma prevalência bem mais baixa $(14,6 \%$ e $10,1 \%$ dos casos, respectivamente). Na necropsia $(\mathrm{n}=40)$, os tumores ocorreram quase sempre como nódulos $(92,5 \%)$ e, menos frequentemente, como massas $(37,5 \%)$, e afetaram principalmente: baço $(62,5 \%)$, pulmão (60\%), fígado $(52,5 \%)$, peritônio $(42,5 \%)$, rim $(37,5 \%)$, encéfalo (30\%), pleura $(25 \%)$ e coração $(22,5 \%)$. Hemoperitônio $(42,5 \%)$ e, consequentemente, anemia $(22,5 \%)$ foram vistos com certa frequência. Na histologia $(n=25)$, os hemangiossarcomas eram principalmente bem diferen- 
ciados (84\%), de baixo grau (64\%) e com estroma escasso (84\%), mas frequentemente (68\%) havia áreas com células demonstrando algum grau de atipia. Necrose, hemorragia e trombose foram vistos em todos os casos, mas hematopoiese extramedular (28\%) e proliferação angiomatosa benigna $(12 \%)$ foram achados menos comuns. Na imuno-histoquímica $(\mathrm{n}=24)$, utilizando anticorpo anti-fator de von Willebrand, todos os casos demonstraram marcação de intensidade variável com um padrão citoplasmático finamente granular. Em relação à classificação anatômica, $55 \%$ dos hemangiossarcomas foram considerados como multicêntricos, $30 \%$ como primários com metástase(s) e $15 \%$ como solitários. Esse artigo discute esses resultados e propõe, com base em combinações de órgãos afetados, um esquema de separação entre hemangiossarcomas primário com metástase(s) e multicêntrico, a fim de tentar homogeneizar a maneira com que patologistas veterinários referem-se a esse neoplasma.

TERMOS DE INDEXAÇÃO: Doenças de cães, oncologia, neoplasias, tumores multicêntricos, hemangiossarcoma.

\section{INTRODUÇÃO}

Hemangiossarcomas são neoplasmas malignos que se originam do endotélio vascular sanguíneo (Goldschmidt \& Hendrick 2002); tais tumores são diagnosticados frequentemente em cães (Brown et al. 1985, Schultheiss 2004, Pirie et al. 2006), mas apenas ocasionalmente nas outras espécies domésticas (Monluxa et al. 1956, Southwood et al. 2000, Godoy et al. 2009). Na rotina do Laboratório de Patologia Veterinária da Universidade Federal de Santa Maria (LPV-UFSM), hemangiossarcoma representa: 1) cerca de $5 \%$ dos neoplasmas malignos encontrados em necropsias de cães, o que o torna o sexto tumor mais frequentemente associado à morte (incluindo eutanásia) nessa espécie (Fighera 2008); e 2) cerca de 3\% dos tumores diagnosticado através de biópsia de pele, o que o torna o quarto câncer de pele mais comum de cães (Souza et al. 2006).

Embora muito se saiba acerca de hemangiossarcoma, a prevalência dos órgãos afetados por esse tumor é tema bastante controverso na literatura internacional, principalmente porque os vários estudos que abordam tal assunto utilizam sistemáticas diferentes em relação à classificação anatômica, mas também devido à falta de dados de necropsia dos casos incluídos (Culbertson 1982), pois quase a totalidade dos artigos discorre sobre a prevalência do hemangiossarcoma em um determinado órgão e não o contrário. Para vários autores (Kleine et al. 1970, Hirsch et al. 1981, Brown et al. 1985), hemangiossarcoma é considerado como sendo um neoplasma primário, frequentemente metastático, enquanto para outros (Goldschmidt \& Hendrick 2002) ocorre principalmente de forma multicêntrica. Essa divergência na classificação quanto ao sítio anatômico dos hemangiossarcomas, que possivelmente se deve a inexistência de subsídios na literatura, faz com que alguns trabalhos abordem o neoplasma como primário de um determinado órgão com possibilidade de metástase(s) em outro(s), enquanto outros consideram casos semelhantes ou idênticos como multicêntricos. Dessa forma, não é inco- mum entre patologistas surgirem as seguintes dúvidas: 1) "Quantos órgãos necessitam ser afetados para um hemangiossarcoma ser considerado multicêntrico?"; 2) "Quais órgãos precisam estar acometidos para um hemangiossarcoma ser considerado multicêntrico?"; e 3) "Quais os órgãos mais afetados em casos de hemangiossarcoma?".

Com base nessa problemática, os objetivos principais deste trabalho são: 1) determinar a prevalência dos órgãos afetados por hemangiossarcoma, a fim de definir quais os mais acometidos e quais aqueles que apenas ocasionalmente estão envolvidos, e 2) subdividir os casos de hemangiossarcoma com base nos sítios anatômicos, a fim de propor uma forma de separação entre essas apresentações (solitário versus primário com metástase versus multicêntrico). Esse estudo visa também comparar os aspectos epidemiológicos e os achados macroscópicos, histológicos e imuno-histoquímicos dos casos de hemangiossarcoma diagnosticados no LPV-UFSM com o que é descrito na literatura.

\section{MATERIAL E MÉTODOS}

Os protocolos de necropsias de cães realizadas entre 1965 e 2012 no LPV-UFSM foram revisados em busca de casos de hemangiossarcoma. 0 método de inclusão dos casos neste estudo foi o diagnóstico definitivo do tumor através de critérios histológicos estabelecidos pela Organização Mundial da Saúde (OMS) para tumores mesenquimais de tecidos moles (Weiss 1974) e pela Armed Forces Institute of Pathology (AFIP) para tumores mesenquimais da pele e dos tecidos moles (Hendrick et al. 1998) e aplicados durante esse período a partir de consultas a diferentes edições do principal livro-texto de patologia de tumores em animais domésticos (Meuten 2002). Esses diagnósticos foram realizados por oito patologistas veterinários pertencentes ao LPV-UFSM em diferentes períodos de tempo, quatro dos quais são autores desse trabalho (G.D.K., L.F.I., C.S.L.B. e R.A.F.).

Os protocolos de necropsia referentes a esses casos foram separados e examinados. Desses protocolos de necropsia foram retiradas informações referentes ao sexo, à idade, às raças e aos achados macroscópicos. Os cães foram classificados apenas como macho e fêmea, independentemente de serem castrados ou não. Foram ainda divididos em três categorias de idade, conforme publicado anteriormente (Fighera et al. 2008): filhotes (até 1 ano de idade), adultos (de 1 a 9 anos de idade) e idosos (10 anos de idade ou mais). Quanto às raças, os cães foram classificados em sem raça definida (SRD) ou de raça pura (RP). Cães mestiços, do cruzamento de duas RP, foram considerados como SRD. Todos os casos incluídos ocorreram no Município de Santa Maria, localizado na Mesorregião do Centro Ocidental Rio-Grandense, popularmente conhecida como Região Central do RS. Para fins de comparação, foram calculados os mesmos dados epidemiológicos (idade, sexo e raça) de toda a população de cães necropsiada no LPV-UFSM nesse mesmo período.

Foram considerados para este estudo apenas casos em que o hemangiossarcoma foi a causa da morte ou a razão para eutanásia do cão $(\mathrm{n}=40)$. A apresentação macroscópica dos hemangiossarcomas foi classificada em: 1) pápula (aumento de volume sólido, redondo e bem circunscrito com menos de $1 \mathrm{~cm}$ de diâmetro), 2) nódulo (aumento de volume sólido, redondo e bem circunscrito com 1 a 10 cm de diâmetro), 3) massa (aumento de volume sólido, irregular, não circunscrito e de qualquer tamanho ou aumento de volume sólido, redondo e bem circunscrito [nódulo], porém, com mais de $10 \mathrm{~cm}$ de diâmetro), 4) mácula/mancha (áreas focais, não elevadas, bem ou mal circunscritas, respectivamente, e com 
menos ou mais de $1 \mathrm{~cm}$ de diâmetro, respectivamente) e 5) organomegalia difusa (aumento de volume difuso de um órgão sem ocorrência de tumorações).

Foram reavaliados histologicamente todos os casos em que os blocos de parafina foram encontrados no Arquivo do LPV-UFSM $(\mathrm{n}=25)$. Os achados histológicos reavaliados incluíram: 1) grau de diferenciação (bem diferenciados ou pouco diferenciados), 2) índice mitótico (baixo grau [ $\leq 2$ mitoses/cga] ou alto grau $\geq 3$ mitoses/cga]), 3) padrão estromal (escasso ou abundante), 4) ocorrência de pleomorfismo celular, 5) atipia e 6) necrose, hemorragia e trombose. Para essa reavaliação foram utilizados diferentes tecidos afetados e que constavam no arquivo. Com exceção de um caso $(n=24)$, pelo menos um tecido de cada um desses casos reavaliados histologicamente foi escolhido e submetido à imuno-histoquímica. A reavaliação histológica e a interpretação imuno-histoquímica foram realizadas por dois (M.M.F. e R.A.F.) e três (M.M.F., G.D.K. e R.A.F.) patologistas veterinários, respectivamente.

A técnica de imuno-histoquímica (IHQ) empregada foi a imunomarcação para o fator de von Willebrand, conforme protocolo descrito a seguir. Após a desparafinização e reidratação dos tecidos, foi realizada a recuperação antigênica com solução de TRIS-EDTA (pH 9,0) em forno micro-ondas, em potência máxima, por dez minutos. Como anticorpo primário, foi utilizado anticorpo policlonal anti-fator de von Willebrand humano produzido em coelho ${ }^{5}$, diluído $1: 400$ em PBST, e incubado por 60 minutos a $37^{\circ} \mathrm{C}$. 0 anticorpo secundário biotinilado e o complexo estreptavidina-biotina-peroxidase ${ }^{6}$ foram utilizados consecutivamente, incubados a $25^{\circ} \mathrm{C}$ por 30 minutos e marcados através da adição do cromógeno de tetracloreto de 3-3' diaminobenzidina (DAB) ${ }^{7}$. A contra-coloração foi com hematoxilina de Mayer. Como controle positivo foram utilizados os vasos sanguíneos normais de áreas não afetadas pelo tumor nas mesmas secções histológicas (controle interno). Como controle negativo, as mesmas secções foram utilizadas, com substituição do anticorpo primário por PBST. A imunomarcação para o fator de von Willebrand foi classificada como leve, moderada ou acentuada, conforme estudos prévios realizados (von Beust et al. 1988, Sabattini \& Bettini 2009).

\section{RESULTADOS}

\section{Achados epidemiológicos}

Entre 1965 e 2012 foram realizadas 7.063 necropsias de cães no LPV-UFSM. Dessas, 53,5\% correspondiam a machos e $46,5 \%$ a fêmeas. Do total de cães, 35,8\% foram incluídos como filhotes, $49,6 \%$ como adultos e $14,6 \%$ como idosos. Dos cães em que dados sobre raça foram encontrados nos protocolos, $62,6 \%$ tinham raça definida e $37,4 \%$ eram SRD. Para fins de comparação, as raças a seguir correspondiam as seguintes prevalências: Pastor Alemão $(10,1 \%)$, Poodle $(4,9 \%)$, Boxer $(3,8 \%)$, Dachshund $(3,1 \%)$, Rottweiler (2,9\%), Cocker Spaniel (2,4\%), Pointer $(2,4 \%)$, Fila Brasileiro (1,5\%), Dogue Alemão $(0,8 \%)$, Husky Siberiano $(0,7 \%)$, Chow-Chow $(0,5 \%)$, Akita $(0,4 \%)$ e Pit Bull $(0,4 \%)$.

Dos 7.063 protocolos de necropsia, $771(10,9 \%)$ correspondiam a tumores. Dessas, em 40 (5,2\% do total de cães que morreram por tumores e 0,6 do total de cães que

\footnotetext{
${ }^{5}$ Dako Cytomation A0082 ${ }^{\circledR}$, Dako Cytomation, 6392 Via Real, Carpinteria, CA, USA.

${ }^{6}$ Dako Cytomation K0690 ${ }^{\circledR}$, Dako Cytomation, 6392 Via Real, Carpinteria, CA, USA.

${ }^{7}$ Dako Cytomation K3468 ${ }^{\circledR}$, Dako Cytomation, 6392 Via Real, Carpinteria, CA, USA.
}

morreram por qualquer causa) havia evidências morfológicas de hemangiossarcoma. Dos 40 cães com hemangiossarcoma, a idade não estava anotada nos protocolos de quatro cães. Dos 36 cães em que a idade constava dos protocolos, $26(72,2 \%)$ foram incluídos como idosos e 10 $(27,8 \%)$ como adultos. Dos 40 cães com hemangiossarcoma, $24(60 \%)$ eram machos e $16(40 \%)$ eram fêmeas. Dos 40 cães com hemangiossarcoma, $11(27,5 \%)$ eram SRD e $29(72,5 \%)$ eram de raça pura, principalmente Pastor Alemão (8/40 [20\%]), Boxer (4/40 [10\%]), Rottweiler (4/40 [10\%]), Dachshund (2/40 [5\%]), Cocker Spaniel (2/40 [5\%]) e Fila Brasileiro (2/40 [5\%]), mas também várias outras raças (Akita, Chow-Chow, Dogue Alemão, Husky Siberiano, Pointer, Poodle e Pit Bull) (1/40 [2,5\%]). Dos 40 cães afetados, 19 (47,5\%) morreram espontaneamente e $21(52,5 \%)$ foram submetidos à eutanásia.

\section{Achados de necropsia}

$\mathrm{Na}$ necropsia $(\mathrm{n}=40)$, independentemente da forma de apresentação, os órgãos afetados incluíram, em ordem decrescente de frequência: baço (25/40 [62,5\%]) (Fig.1), pulmão (24/40 [60\%]) (Fig.2), fígado (21/40 [52,5\%]) (Fig.3), peritônio $(17 / 40[42,5 \%])$, rim $(15 / 40$ [37,5\%]), encéfalo $(12 / 40$ [30\%]), pleura $(10 / 40$ [25\%]), coração (9/40 [22,5\%]), intestino (8/40 [20\%]), linfonodo (8/40 [20\%]), adrenal (8/40 [20\%]), músculo esquelético (6/40 [15\%]), pele $(6 / 40[15 \%])$, cavidade oral $(5 / 40[12,5 \%])$, pâncreas $(5 / 40$ [12,5\%]), osso $(5 / 40$ [12,5\%]), tecido subcutâneo $(5 / 40[12,5 \%])$, estômago $(2 / 40[5 \%])$, ureter $(2 / 40[5 \%])$, aorta $(1 / 40[2,5 \%])$, bexiga $(1 / 40[2,5 \%])$, esôfago $(1 / 40$ [2,5\%]), faringe $(1 / 40$ [2,5\%]), ovário $(1 / 40$ [2,5\%]), próstata $(1 / 40[2,5 \%])$, testículo $(1 / 40[2,5 \%])$, traqueia $(1 / 40[2,5 \%])$ e útero $(1 / 40$ [2,5\%]). 0 número de órgãos afetados em cada cão variou entre 1-15.

Em alguns casos (6/40 [15\%]), os cães afetados apresentavam apenas um órgão afetado; esses casos foram por nós denominados de hemangiossarcoma solitário. $\mathrm{Na}$ maior parte dos casos (22/40 [55\%]), os cães afetados ti-

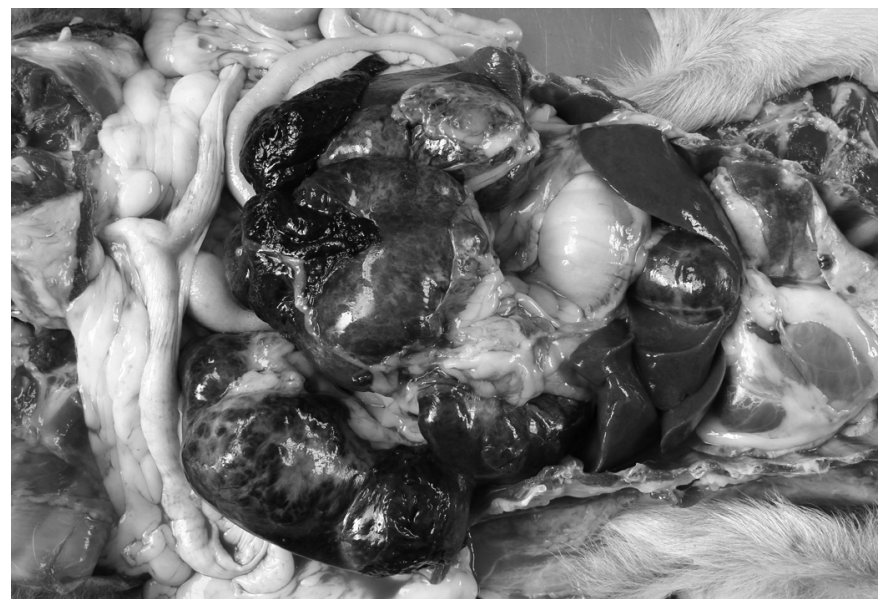

Fig.1. Múltiplas massas vermelho-escuras obliteram o parênquima esplênico e aumentam significativamente o volume do órgão (esplenomegalia). Note que uma das massas está rompida. 0 baço foi o órgão mais frequentemente acometido em casos de hemangiossarcoma canino, perfazendo quase um terço dos casos. 


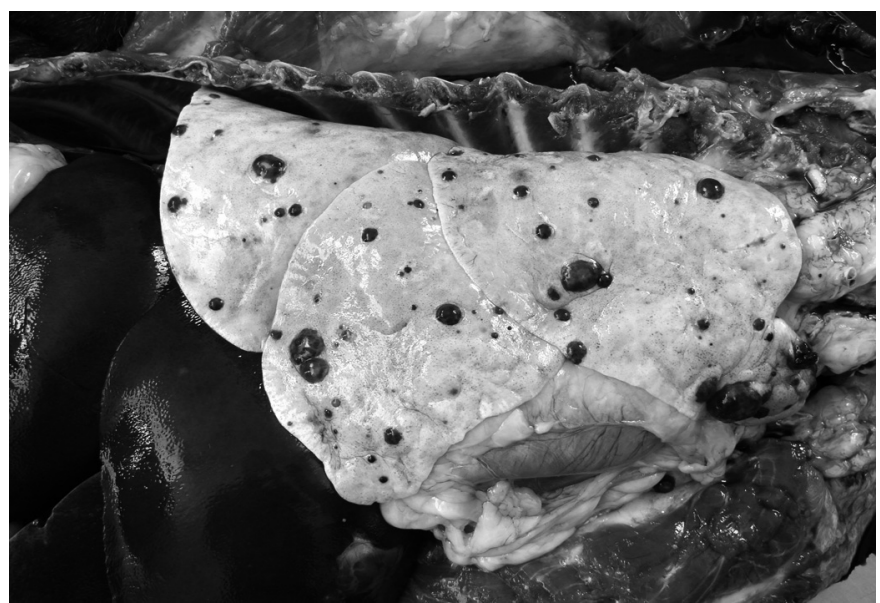

Fig.2. Pápulas e nódulos vermelho-escuros e multifocais que protraem hemisfericamente da superfície pleural do pulmão. 0 pulmão foi o segundo órgão mais frequentemente acometido em casos de hemangiossarcoma canino, perfazendo pouco mais da metade dos casos.

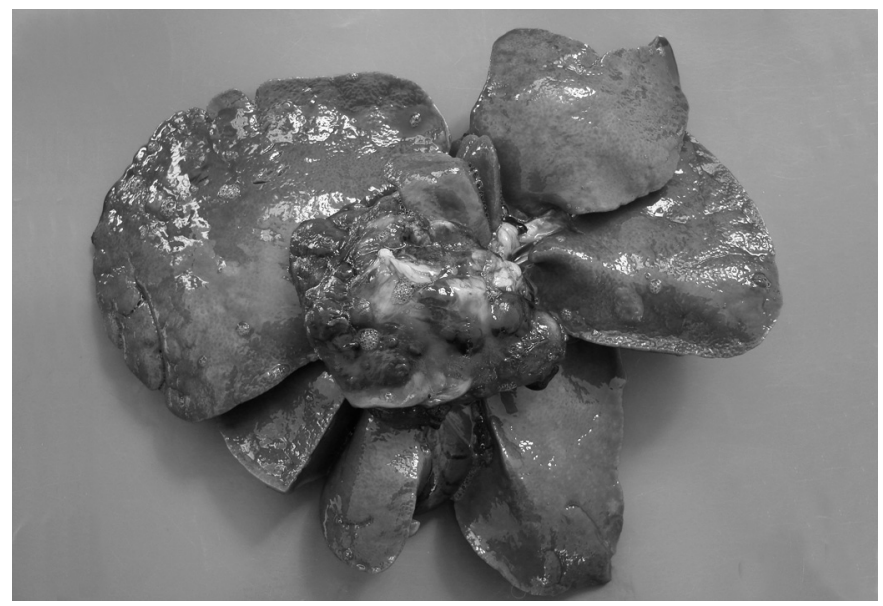

Fig.3. Massa tumoral focalmente extensa que emerge do lobo hepático quadrado. 0 fígado foi o terceiro órgão mais frequentemente acometido em casos de hemangiossarcoma canino, perfazendo cerca da metade dos casos.

nham vários órgãos acometidos e não era possível inferir sobre a origem primária do tumor; esses casos foram por nós denominados de hemangiossarcoma multicêntrico. No restante dos casos (12/40 [30\%]), os cães tinham entre dois e quatro órgãos afetados e era possível deduzir qual dos órgãos era mais provavelmente o sítio primário e quais eram metástases; esses casos foram por nós denominados de hemangiossarcoma metastático.

Nos casos em que o tumor foi considerado solitário (6/40 [15\%]), os órgãos afetados incluíram: baço $(3 / 6$ [50\%]), fígado (1/6 [16,7\%]), cavidade oral (1/6 [16,7\%]) e osso $(1 / 6[16,7 \%])$. Nos casos em que o tumor foi considerado metastático (12/40 [30\%]), os órgãos afetados foram (sítio primário e metástase): baço e fígado $(2 / 12$ $[16,7 \%])$, pele e pulmão $(1 / 12$ [8,3\%]), tecido subcutâneo e pulmão (1/12 [8,3\%]), baço e cavidade oral $(1 / 12$ $[8,3 \%])$, fígado e peritônio $(1 / 12$ [8,3\%]), fígado e linfonodo (1/12 [8,3\%]), coração e pulmão $(1 / 12$ [8,3\%]), baço, pulmão e peritônio $(1 / 12$ [8,3\%]), fígado, linfonodo e pe- ritônio $(1 / 12$ [8,3\%]), fígado, pulmão e peritônio $(1 / 12$ $[8,3 \%])$ e pele, pulmão e pleura $(1 / 12$ [8,3\%]). Nos casos em que o tumor foi considerado multicêntrico (22/40 [55\%]), a frequência com que cada órgão foi afetado foi a seguinte: baço (18/22 [81,8\%]), pulmão (18/22 [81,8\%]), rim $(15 / 22[68,2 \%])$, fígado $(14 / 22[63,6 \%])$, peritônio $(13 / 22[59,1 \%])$, encéfalo $(12 / 22[54,5 \%])$, pleura $(9 / 22$ $[40,9 \%])$, adrenal $(8 / 22[36,4 \%])$, coração $(8 / 22$ [36,4\%]), intestino $(8 / 22[36,4 \%])$, linfonodo $(6 / 22[27,3 \%])$, músculo esquelético $(6 / 22$ [27,3\%]), pâncreas (5/22 [22,7\%]), pele $(4 / 22[18,2 \%])$, tecido subcutâneo $(4 / 40[18,2 \%])$, osso $(4 / 22$ [18,2\%]), cavidade oral $(3 / 22$ [13,6\%]), estômago $(2 / 22[9,1 \%])$, ureter $(2 / 22[9,1 \%])$, aorta $(1 / 22$ [4,5\%]), bexiga $(1 / 22[4,5 \%])$, esôfago $(1 / 22[4,5 \%])$, faringe $(1 / 22[4,5 \%])$, ovário $(1 / 22[4,5 \%])$, próstata $(1 / 22$ $[4,5 \%])$, testículo $(1 / 22[4,5 \%])$, traqueia $(1 / 22[4,5 \%])$ e útero $(1 / 22[4,5 \%])$.

Os hemangiossarcomas ocorreram como tumores em todos os casos (40/40 [100\%]), principalmente na forma de nódulos (37/40 [92,5\%]), menos frequentemente como massas $(15 / 40[37,5 \%])$ e raramente como pápulas $(1 / 40$ $[2,5 \%]]$. Alguns desses neoplasmas foram também vistos como máculas/manchas $(8 / 40$ [20\%]) e outros na forma de organomegalia difusa $(5 / 40[12,5 \%])$. Com frequência os cães afetados demonstravam, concomitantemente, dois ou mais desses padrões macroscópicos de apresentação, como por exemplo, nódulos e massas, que ocorreram ao mesmo tempo e em diferentes órgãos de muitos cães $(15 / 40[37,5 \%])$.

Nódulos (Fig.4) ocorreram em todos os tecidos acometidos pelos hemangiossarcomas e o número de órgãos afetados sincronicamente variou de 1 a 12 . 0 número de nódulos por órgão foi classificado como contável (até quatro) ou incontável (múltiplos). Em 21 casos (52,5\%), havia um ou mais órgãos com número contável de nódulos. Em 31 casos $(77,5 \%)$, o número de nódulos em um ou mais órgãos era incontável. Os nódulos apresentavam dimensões variadas, entre 1 e $10 \mathrm{~cm}$ e foram classificados como multifocais ou coalescentes. Foram descritas as seguintes colorações para os nódulos: vermelho-escuro (20/40 [50\%]), vermelho $(9 / 40$ [22,5\%]), vermelho com focos brancos $(5 / 40$ $[12,5 \%])$, branco $(4 / 40[10 \%])$, enegrecido (4/40 [10\%]) e azulado (2/40 [5\%]). Sempre que descrita, a superfície natural dos nódulos foi citada como lisa e brilhante. Ao corte, os nódulos eram macios (10/40 [25\%]), císticos (6/40 [15\%]), friáveis $(3 / 40[7,5 \%])$ ou firmes $(2 / 40$ [5\%]). Em alguns poucos casos $(3 / 40[7,5 \%])$, os nódulos foram descritos como umbilicados. Oito $(20 \%)$ nódulos tinham coágulos em seu interior ou aderidos externamente a eles.

Dos casos em que ocorreram massas (Fig.5), um ou mais órgãos foram afetados, e incluíam: baço (4/40 [10\%]), coração $(4 / 40$ [10\%]), fígado $(2 / 40$ [5\%]), peritônio $(2 / 40$ [5\%]), cavidade oral $(1 / 40$ [2,5\%]) e tecido subcutâneo (1/40 [2,5\%]). Estas massas variaram de $1 \mathrm{a} 32 \mathrm{~cm}$ em seu maior eixo. As massas eram citadas como solitárias e extensas. Foram descritas as seguintes colorações para as massas: vermelho-escuro (6/40 [15\%]), vermelho $(5 / 40$ [12,5\%]), moteado de vermelho, branco e amarelo (2/40 [5\%]), marrom-claro (2/40 [5\%]) e azulado (1/40 [2,5\%]). Sempre que 


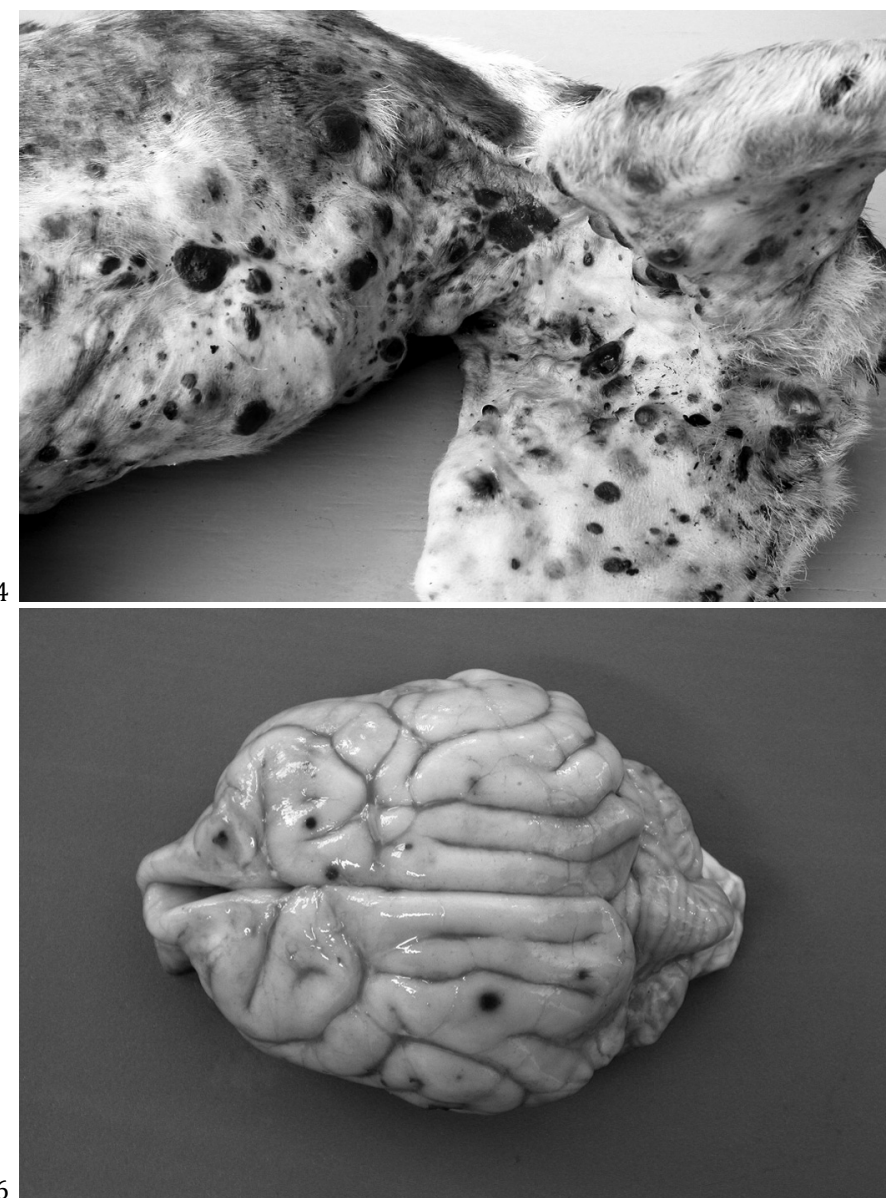

Fig.4. Pápulas e nódulos cutâneos distribuídos disseminadamente na pele. Essa apresentação dramática do hemangiossarcoma cursou com perda crônica de sangue através de gotejamento de cada um dos tumores e morte do cão devido a complicações de anemia hemorrágica crônica.

Fig.6. Manchas vermelho-escuras que lembram contusões cerebrais. Essa é a típica apresentação do hemangiossarcoma no encéfalo de cães.

descrita, a superfície natural foi citada como lisa e brilhante. Ao corte, as massas eram friáveis (5/40 [12,5\%]), macias (5/40 [12,5\%]), císticas (4/40 [10\%]) ou firmes $(1 / 40$ $[2,5 \%])$. Em pelo menos um caso $(2,5 \%)$ a massa foi descrita como umbilicada. Duas (5\%) massas tinham coágulos em seu interior e rupturas facilmente perceptíveis.

Máculas e/ou manchas (Fig.6) foram descritas para os seguintes órgãos: encéfalo $(3 / 40[7,5 \%])$, fígado $(2 / 40$ [5\%]), músculo esquelético (2/40 [5\%]) e pulmão (1/40 $[2,5 \%])$. Estas áreas variaram de 0,5 a $5 \mathrm{~cm}$ em seu maior eixo, eram multifocais e descritas como vermelhas ou vermelho-escuras. Organomegalia difusa afetou apenas os linfonodos. Em todos esses casos, os demais órgãos afetados apresentavam nódulos e/ou massas. Os linfonodos afetados eram grandes (linfadenomegalia) e túrgidos. Ao corte eram macios e deixavam fluir líquido vermelho-claro ou róseo e turvo (sangue misturado com linfa). A superfície de corte era difusamente ou multifocalmente vermelha.

Achados de necropsia diretamente relacionados ao tumor incluíram principalmente hemoperitônio (17/40 [42,5\%]) (Fig.7), anemia (9/40 [22,5\%]) e, menos frequentemente,

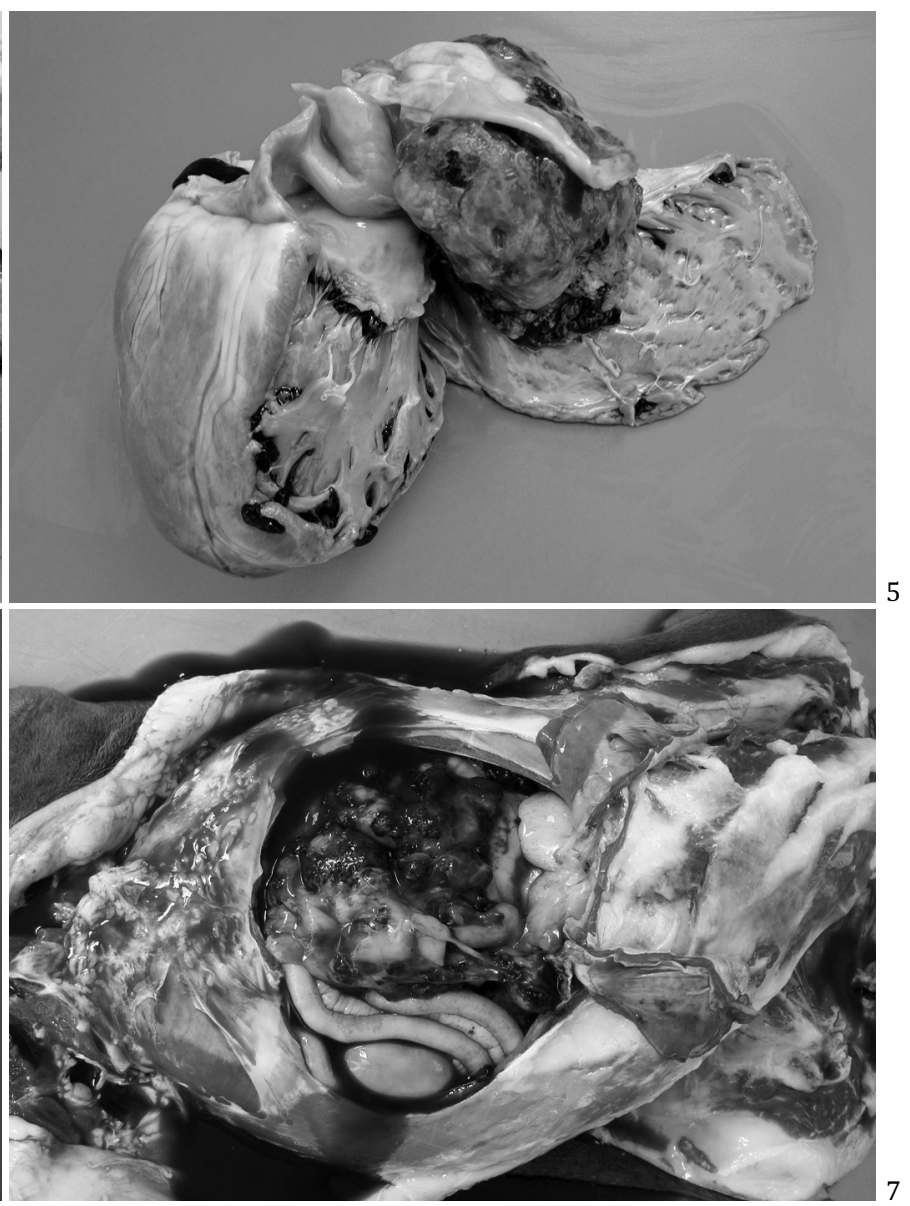

Fig.5. Grande massa tumoral que ocupa o átrio direito. Note que boa parte do massa é constituída por um trombo, uma apresentação clássica do hemangiossarcoma cardíaco em cães.

Fig.7. Hemoperitônio devido à ruptura de hemangiossarcoma esplênico em um cão. Nesses casos, o desenvolvimento de anemia aguda é um achado importante no histórico da necropsia.

hemotórax (5/40 [12,5\%]), icterícia (2/40 [5\%]), insuficiência cardíaca congestiva (2/40 [5\%]) e desvios porto-sistêmicos (1/40 [2,5\%]). A quantidade de sangue acumulado nas cavidades abdominal e torácica variou de 10 a $4.500 \mathrm{ml}$ e de 50 a $560 \mathrm{ml}$, respectivamente. Dos casos em que havia achados que permitiram o diagnóstico de anemia durante a necropsia (mucosas [Fig.8] e vísceras pálidas e sangue aquoso), a perda continuada de sangue foi o único mecanismo que pode ser comprovado. Nesses casos, a perda ocorreu por hemoperitônio (5/40 [12,5\%]) como consequência de ruptura dos tumores em órgãos parenquimatosos abdominais (baço e/ou fígado), por hemotórax (1/40 [2,5\%]) como consequência de ruptura dos tumores em órgãos parenquimatosos torácicos (pulmões) ou por ambos (1/40 [2,5\%]). Perda para o terceiro espaço (fáscias musculares) e hemorragia a partir de tumores cutâneos múltiplos foi uma causa incomum de anemia (1/40 [2,5\%]). Hemoperitônio estava presente em um $(2,5 \%)$ dos dois cães com icterícia e a metabolização da hemoglobina pelo sistema monocítico-macrofágico foi a explicação sugerida para esse caso. 0 outro cão com icterícia $(2,5 \%)$ também tinha acometimento do fígado pelo heman- 


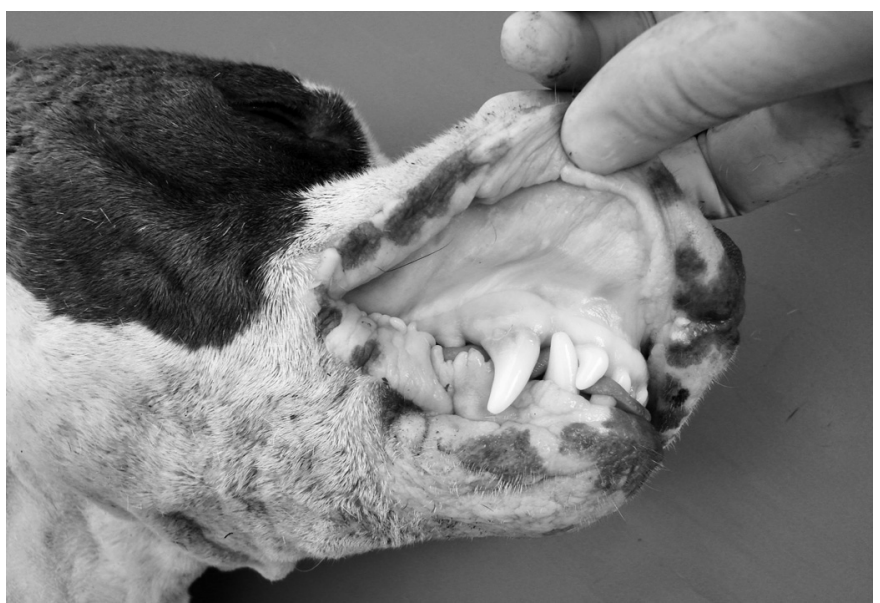

Fig.8. Palidez das mucosas em um cão com hemangiossarcoma multicêntrico. Nesse, e na maioria dos casos, a causa básica é o acúmulo de sangue nas cavidades (hemoperitônio e/ou hemotórax) devido à ruptura dos tumores.

giossarcoma. Insuficiência cardíaca congestiva foi secundária à presença de massas tumorais, frequentemente trombosadas, que se originavam do átrio direito. Lesões associadas à síndrome incluíram fígado de noz-moscada $(1 / 40[2,5 \%])$, ascite $(1 / 40[2,5 \%])$ e hidrotórax $(1 / 40[2,5 \%])$.

\section{Achados histopatológicos}

Na histologia $(n=25)$, todos os hemangiossarcomas caracterizaram-se por uma proliferação celular variavelmente diferenciada, porém com características morfológicas suficientes para um possível reconhecimento de sua origem apenas através desse método, ou seja, um arranjo na forma de vasos sanguíneos de diferentes calibres, que variavam desde capilares (Fig.9) até grandes espaços cavernosos (Fig.10). Com base nessa diferenciação, os hemangiossarcomas foram divididos em: bem diferenciados (21/25 [84\%]) e pouco diferenciados (4/25 [16\%]). Em vários casos (10/25 [40\%]), as células neoplásicas demonstravam marcado pleomorfismo. Em alguns poucos casos (3/25 [12\%]), havia áreas bem diferenciadas intercaladas com áreas pouco diferenciadas. Presença de células que quando observadas

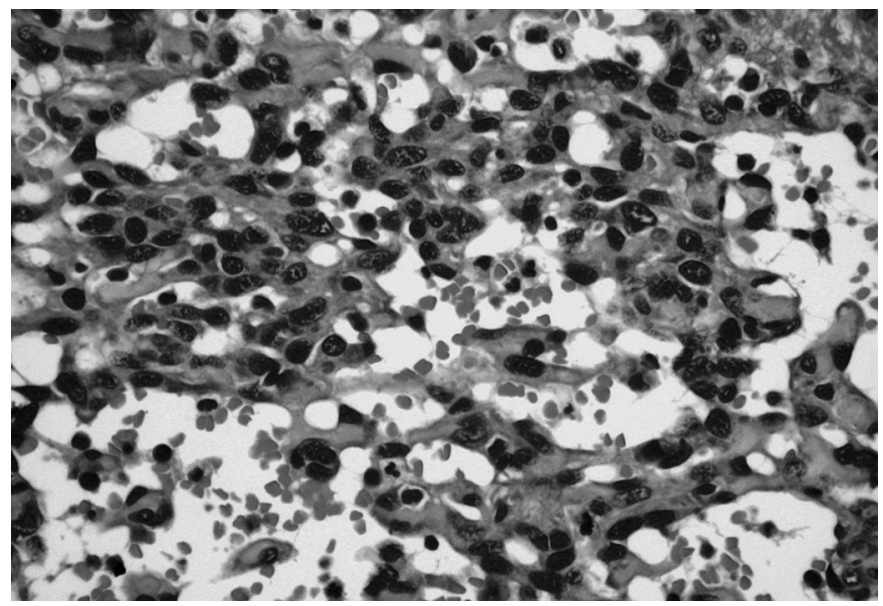

Fig.9. Proliferação de células ovais a variavelmente fusiformes formando capilares repletos de eritrócitos na pele de um cão, morfologia típica de hemangiossarcoma. HE, obj.20x.

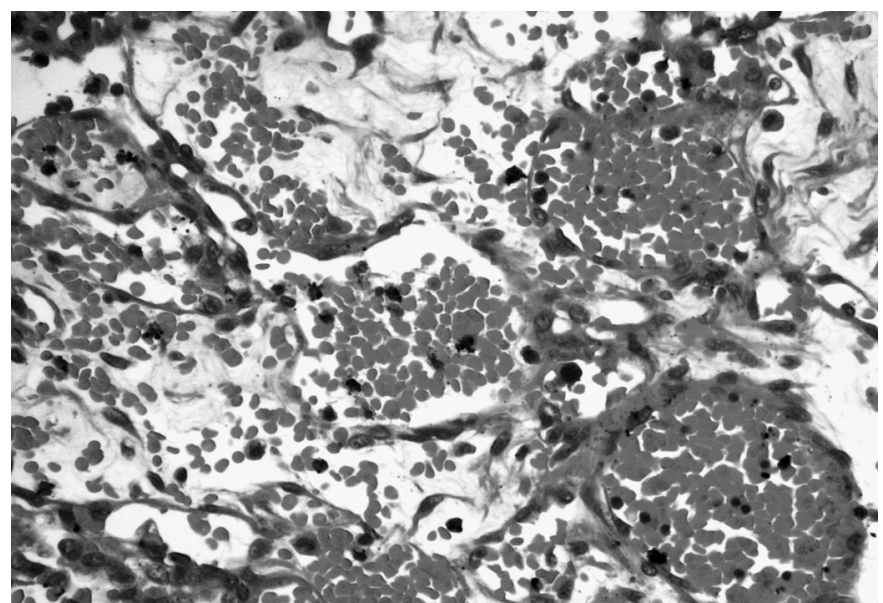

Fig.10. Proliferação de células fusiformes formando espaços vasculares dilatados (espaços cavernosos) repletos de eritrócitos no omento de um cão, morfologia típica de hemangiossarcoma. HE, obj.20x.

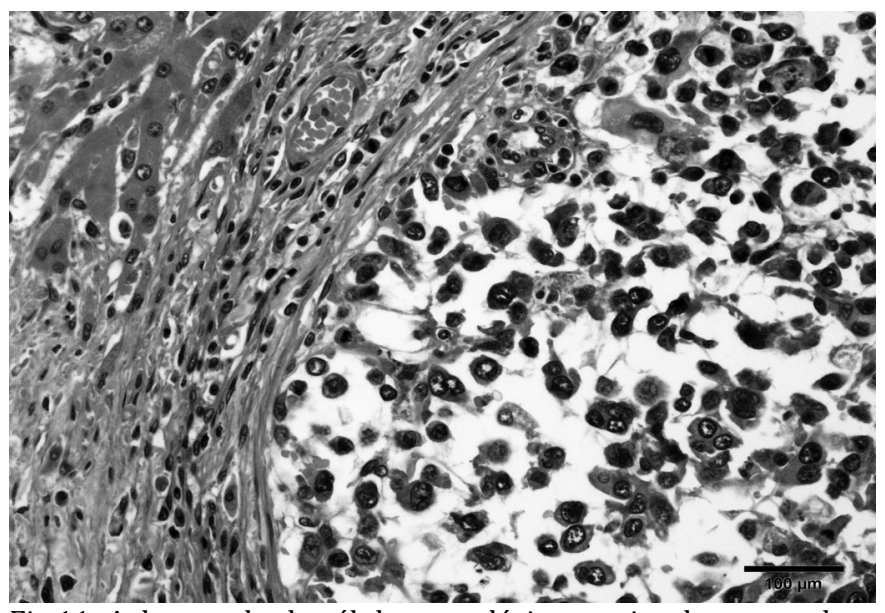

Fig.11. Aglomerado de células neoplásicas variavelmente redondas, marcadamente descoesas e frequentemente binucleadas no fígado de um cão. Essa perda da diferenciação foi comum em muitos casos de hemangiossarcoma e interpretada como atipia celular. HE, obj.20x.

isoladamente não permitiam inferir sobre sua origem (atipia celular) (Fig.11) também foi um achado comum (17/25 [68\%]), incluindo alguns poucos casos em que tais células tinham aspecto epitelioide (3/25 [12\%]). Mesmo nesses 17 casos era possível determinar com facilidade a origem vascular do neoplasma. 0 índice mitótico foi classificado em alto grau (9/25 [36\%]) ou baixo grau (16/25 [64\%]). Presença de colágeno intercalado entre feixes de células neoplásicas foi um achado constante e quantificado como: escasso (21/25 [84\%]) ou abundante (4/25 [16\%]). Áreas de trombose (Fig.12), hemorragia e necrose foram observadas em todos os casos. Adicionalmente, foram vistos focos de hematopoiese extramedular (7/25 [28\%]) (Fig.13), aglomerados de neutrófilos intravasculares (4/25 [16\%]) e acúmulo de células endoteliais neoplásicas no interior de vasos linfáticos (1/25 [4\%]). Em alguns poucos casos (3/25 [12\%]), foram observadas áreas de proliferação angiomatosa benigna (Fig.14) ao redor ou entre áreas de formação neoplásica na pele, coração e baço, respectivamente. 


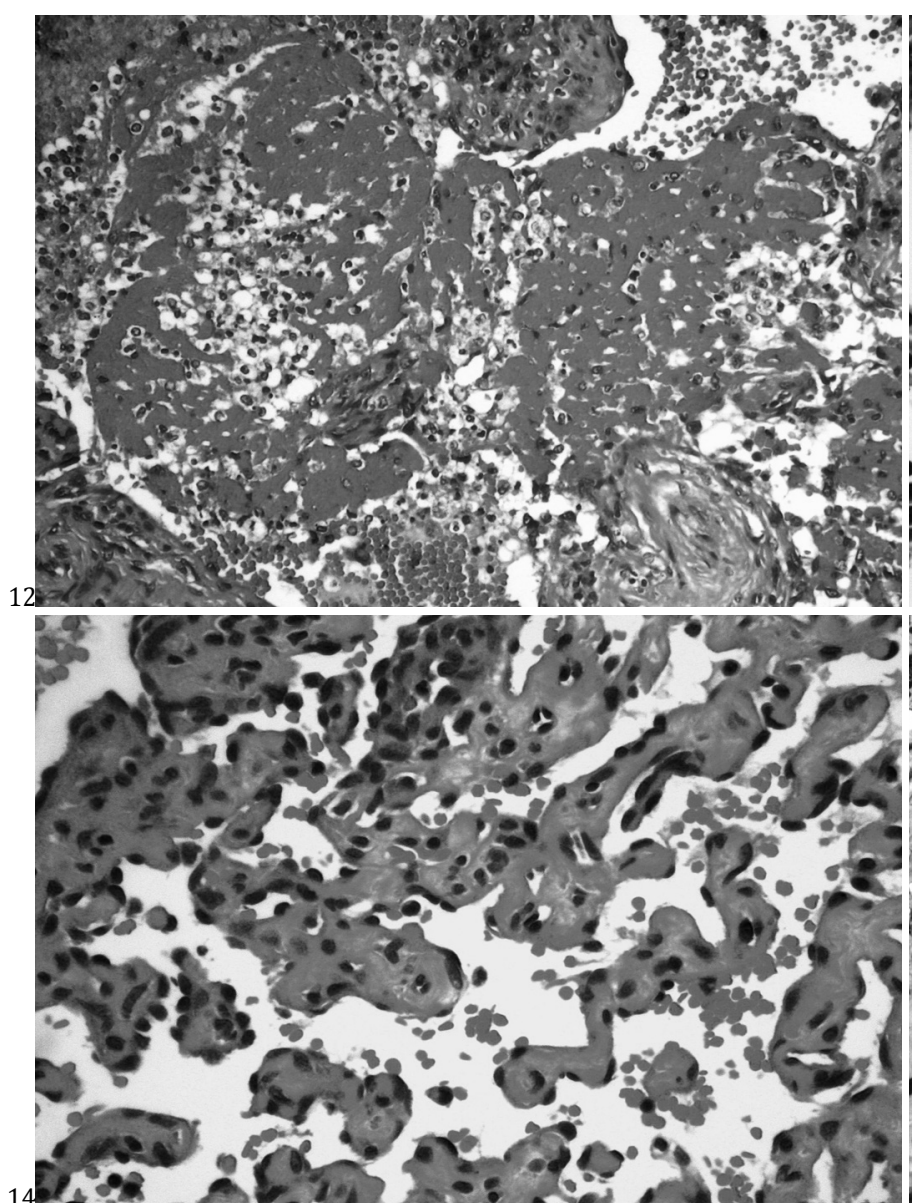

Fig.12. Trombo de fibrina infiltrado por neutrófilos degenerados obstruindo completamente o lúmen de um vaso neoformado no fígado de um cão. Trombose foi uma constante em todos os 40 casos de hemangiossarcoma descritos. HE, obj.10x.

Fig.14. Proliferação angiomatoide benigna caracterizada por uma redundância de células endoteliais dispostas sobre feixes de colágeno na forma de capilares hamartomatosos repletos de eritrócitos na pele de um cão com hemangiossarcoma. HE, obj.20x.

\section{Achados imuno-histoquímicos}

$\mathrm{Na}$ imuno-histoquímica, dos 24 casos testados, todos foram positivos. Quanto à intensidade, a maior parte dos casos foi considerada como leve $(12 / 24$ [50\%]) ou moderada (10/24 [41,7\%]). Marcação acentuada (2/24 [8,3\%]) foi bem menos comum. Quanto ao padrão de imunomarcação, as células positivas tinham citoplasma finamente granular (Fig.15). A quantidade de grânulos era variável e foi o critério utilizado para considerar as intensidades anteriormente descritas. 0 endotélio de vasos sanguíneos normais e os megacariócitos demonstraram marcação idêntica. Em alguns desses casos, houve reações inespecíficas, incluindo nas áreas de necrose e nos lúmens vasculares, principalmente sobre trombos de fibrina.

\section{DISCUSSÃO}

A prevalência do hemangiossarcoma em diferentes órgãos pode variar muito de um estudo para outro (Kleine et al. 1970, Hirsch et al. 1981, Brown et al. 1985), devido princi-

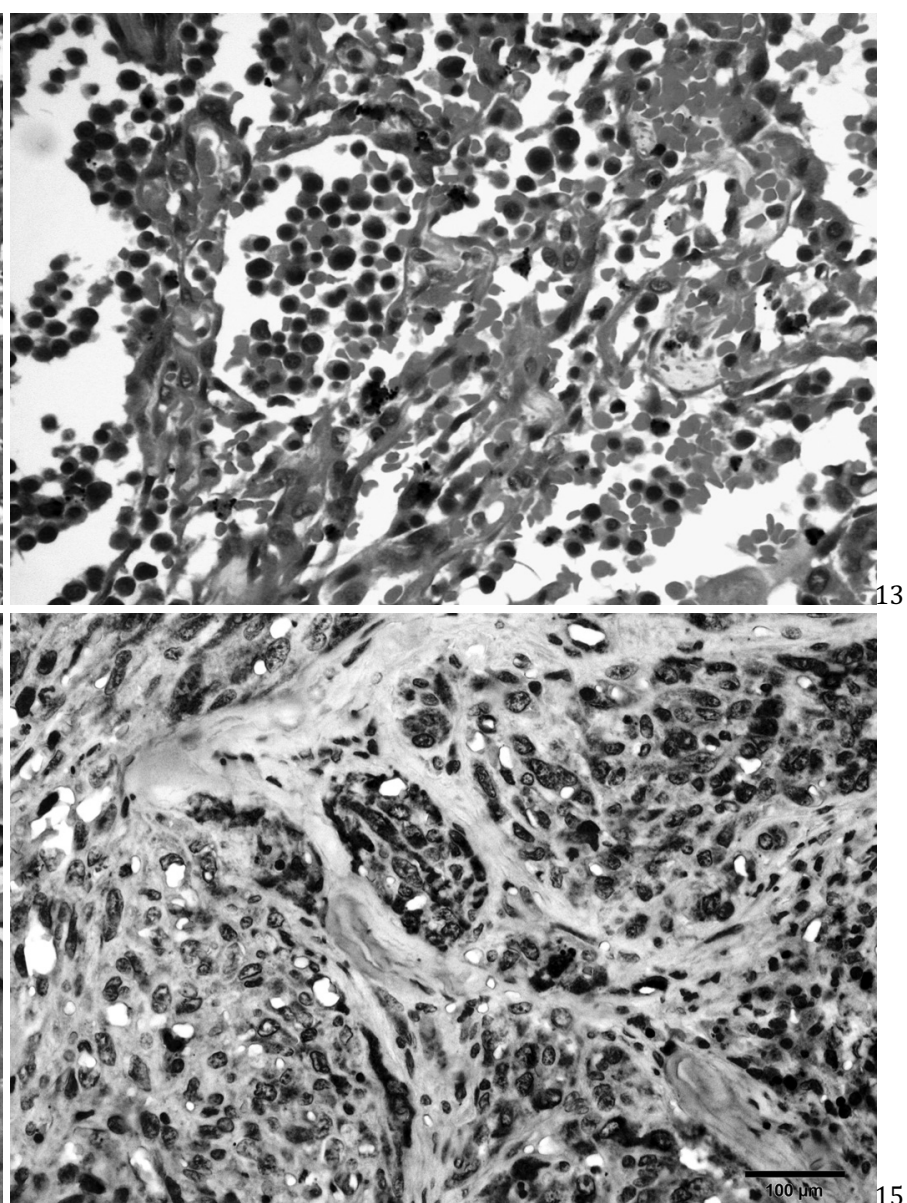

Fig.13. Acúmulo de precursores hematopoiéticos, principalmente eritropoiéticos (metarrubrícitos e rubrícitos), na luz de vasos sanguíneos neoformados, no diafragma de um cão com hemangiossarcoma. HE, obj.20x.

Fig.15. A imunorreatividade é observada na forma de múltiplos grânulos castanho-escuros dispersos no citoplasma das células neoplásicas no linfonodo de um cão com hemangiossarcoma. Imuno-histoquímica (método da estreptavidina-biotina-peroxidase), obj.20x.

palmente a divergências na definição dos sítios anatômicos (solitário, metastático ou multicêntrico). Em um estudo retrospectivo antigo, por exemplo, alguns autores (Kleine et al. 1970) concluíram que seus casos de hemangiossarcoma cardíaco de cães eram mais frequentemente primários do que metastáticos, devido à sua localização e apresentação macroscópica. Consequentemente, como o coração foi considerado como o sítio primário nesse estudo, ele foi o órgão mais afetado. Com base no estudo anterior, anos mais tarde, outros autores (Hirsch et al. 1981) também classificaram grande parte dos tumores cardíacos incluídos em seu estudo como primários, obtendo resultados muito semelhantes. Diferentemente, alguns autores (Brown et al. 1985) definiram o acometimento cardíaco como metastático, o que resultou em uma menor prevalência de hemangiossarcomas como tumores cardíacos primários.

A fim de evitar os problemas previamente discutidos, a distribuição dos hemangiossarcomas por órgão feita neste estudo não levou em conta a origem do neoplasma e nem 
a quantidade de órgãos afetados em cada caso. Dessa forma, reunimos todos os casos $(\mathrm{n}=40)$, independentemente de serem solitários, metastáticos ou multicêntricos e analisamos a prevalência de cada órgão afetado sem subdividi-los de acordo com um possível sítio primário. Com isso, acreditamos estar apresentando resultados mais fidedignos do que nesses outros estudos. Os resultados por nós encontrados demonstram que os órgãos mais acometidos por hemangiossarcoma incluem, em ordem decrescente de frequência: baço, pulmão, fígado, peritônio, rim, encéfalo, pleura e coração. Esta prevalência é muito semelhante à observada no estudo de Hirsch et al. (1981), exceto, obviamente, pelo menor número de tumores cardíacos. $\mathrm{Na}$ literatura internacional, o baço é frequentemente descrito como o órgão mais afetado pelo hemangiossarcoma (Hirsch et al. 1981, Brown et al. 1985, Schultheiss 2004, Sabattini \& Bettini 2009), exceto, é claro, no estudo de Kleine et al. (1970), como já discutido previamente. Semelhante ao que observamos, apenas esporadicamente outros órgãos são descritos na literatura como estando envolvidos em casos de hemangiossarcoma (Brown et al. 1985, Hayden et al. 1992, Sabattini \& Bettini 2009).

0 frequente envolvimento concomitante de órgãos como coração e baço em cães afetados por hemangiossarcoma tem levado muitos autores a discutirem uma possível origem multicêntrica para esse neoplasma (Goldschmidt \& Hendrick 2002). Tumores multicêntricos são frequentes em cães e o hemangiossarcoma é, em nossa rotina, o segundo mais diagnosticado nessa espécie, atrás apenas do linfoma (Fighera 2008). Devido ao fato de não haver critérios na literatura consultada para a utilização do termo multicêntrico, definimos, para uso nesse estudo, que tumores multicêntricos são aqueles que acometem vários órgãos de um mesmo indivíduo, ao ponto de tornar impossível estabelecer um sítio primário. Na maior parte dos casos, tumores multicêntricos originam-se em um único órgão e posteriormente metastatizam para vários outros, tornando impossível saber qual deles foi inicialmente afetado, ou seja, são proliferações celulares que possuem um sítio primário, porém não detectado. Menos frequentemente, tumores multicêntricos podem originar-se ao mesmo tempo em vários órgãos diferentes. Com base nessa definição, podemos depreender que quando vários órgãos são afetados por um neoplasma e não é possível saber qual deles foi primeiramente acometido, a multicentricidade pode ser aventada, independentemente se isso ocorreu sequencialmente ou sincronicamente. Além dessas aplicações, em medicina humana, cada vez mais se utiliza o adjetivo multicêntrico para expressar múltiplos tumores em um único órgão, principalmente para tumores mamários, tireoidianos e intestinais, mas também em outros órgãos.

0 exposto no parágrafo anterior é diferente da situação em que mais de um órgão é acometido, mas um deles é mais frequentemente descrito na literatura como sítio metastático preferencial, como por exemplo, em casos de tumores hepatoesplênicos ou cardiopulmonares, nos quais o baço e o coração são sempre considerados como os locais primários e o fígado e o pulmão como os sítios metastáticos, respectivamente. Esse fato é particularmente verda- deiro para tumores mesenquimais, como o hemangiossarcoma, que metastatizam principalmente por via sanguínea e, portanto, o padrão de metastatização "tende a respeitar" a circulação sanguínea (Cullen et al. 2002). Com base nessas definições e nos achados por nós encontrados nestes 40 casos de hemangiossarcoma, consideramos como solitários aqueles casos em que apenas um órgão foi afetado e como primários com metástases aqueles casos em que: 1) havia apenas dois órgãos afetados, 2) caso pelo menos um desses órgãos fosse cavitário, houvesse metastatização transcelômica, 3) caso o terceiro órgão fosse algum ou vários linfonodos drenantes e 4) havendo mais de dois órgãos (desconsiderando os linfonodos e mesotélios [Critérios $2 \mathrm{e}$ 3]), fosse plausível inferir sobre um possível padrão de metastatização, por exemplo, hemangiossarcoma esplênico com metástases no fígado e pulmão. Quando mais de dois órgãos estiveram afetados e nenhum dos critérios anteriormente descritos foi preenchido, os casos foram considerados como multicêntricos.

Os aspectos epidemiológicos e os achados macroscópicos e histológicos observados nos 40 casos de hemangiossarcoma revisados são semelhantes aos descritos na literatura (Goldschmidt \& Hendrick 2002). Para a maior parte dos autores (Culbertson 1982, Hargis et al. 1992, Schultheiss 2004), hemangiossarcomas ocorrem mais comumente em cães idosos, menos frequentemente em cães adultos e apenas raramente em filhotes. Em alguns estudos, há maior número de machos afetados (Culbertson 1982, Ward et al. 1994), embora a maior parte dos autores não tenha relatado predisposição sexual (Kleine et al. 1970, Hirsch et al. 1981, Hargis et al. 1992). A influência hereditária é bastante discutida por alguns autores, pois se acredita haver forte predisposição de cães das raças Pastor Alemão (Kleine et al. 1970, Hirsch et al. 1981, Brown et al. 1985), Labrador Retriever (Schultheiss 2004) e Golden Retriever (Tamburini et al. 2009). Neste estudo, a prevalência do tumor em cães da raça Pastor Alemão foi de $20 \%$, semelhante à frequência encontrada por Kleine et al. (1970). Apesar de termos observado maior número de hemangiossarcomas em cães idosos e dessa raça, devemos ter cautela ao interpretar tais resultados, visto o desconhecimento dos dados referentes à faixa etária, ao sexo e às raças de uma população poder alterar a interpretação. Para evitar isso, comparamos os dados referentes à epidemiologia desses 40 casos de hemangiossarcoma com aqueles oriundos da população de cães necropsiada no LPV-UFSM durante o mesmo período, pois assumimos que ela possivelmente corresponde a uma amostra fidedigna da população local de nossa região. Assim, se compararmos a prevalência de cães idosos e da raça Pastor Alemão na população geral $(14,6 \%$ e $10,1 \%$ dos casos, respectivamente) com aquela observada nos cães com hemangiossarcoma $(72,2 \%$ e $20 \%$ dos casos, respectivamente), podemos afirmar com mais segurança que tais aspectos epidemiológicos correspondem a fatores de risco no desenvolvimento desse tumor.

Histologicamente, a maioria dos hemangiossarcomas analisados foi classificada em bem diferenciado (84\%) e de baixo grau (64\%), apesar do comportamento marcadamente agressivo de grande parte deles. Semelhantemen- 
te ao que é descrito na literatura (Schultheiss 2004), não houve correlação entre o grau de diferenciação e a agressividade do tumor, considerando apenas como mais ou menos agressivos aqueles casos em que havia mais ou menos órgãos afetados, respectivamente. Provavelmente por este motivo, o número de mitoses comumente não é parâmetro avaliado em vários estudos sobre hemangiossarcoma (Culbertson 1982, Hargis et al. 1992, Pirie et al. 2006, Sabattini \& Bettini 2009). Segundo Sabattini \& Bettini (2009), o nível de proliferação celular do tumor seria muito melhor avaliado pela imunomarcação para Ki-67, e não pela contagem de mitoses. Neste estudo, a classificação dos tumores quanto ao grau de diferenciação, índice mitótico e pleomorfismo celular teve utilidade apenas na interpretação dos casos de imuno-histoquímica, e será discutida mais adiante. A presença de necrose, hemorragia e trombose foi um achado consistente em todos os casos e, portanto, não possui relação com os outros parâmetros avaliados.

A presença de hematopoiese extramedular em meio ao tumor foi observada em $28 \%$ dos casos aqui descritos. Este achado tem sido ocasionalmente observado por outros autores (Bertazzolo et al. 2005), com uma frequência de até $42 \%$. Segundo Johns \& Christopher (2012), a hematopoiese extramedular no interior de neoplasmas é pouco relatada por ser um achado incidental e sem importância clínica. Acredita-se que a origem em comum das células endoteliais e sanguíneas a partir de uma mesma célula-tronco, somada ao envolvimento de grande número de citocinas na proliferação do endotélio neoplásico, possa estar envolvida no estímulo à hematopoiese extramedular intratumoral (Bertazzolo et al. 2005).

Em três casos, que afetaram baço, coração e pele, respectivamente, havia áreas de proliferação vascular benigna intercaladas com áreas neoplásicas pouco diferenciadas no mesmo tumor. Esta característica histológica assemelha-se muito ao que é descrito para os hemangiossarcomas cutâneos caninos induzidos pelo sol, que são frequentemente circundados por proliferações vasculares não neoplásicas (telangiectasia) ou neoplásicas benignas (hemangiomas) (Gross et al. 2009). A presença dessas formações angiomatosas benignas em meio a um neoplasma maligno pode dificultar o diagnóstico do neoplasma quando frente a uma biopsia incisional, visto que uma pequena amostragem do tumor pode não ser representativa.

Em três estudos prévios (von Beust et al. 1988, Ferrer et al. 1995, Warren \& Summers 2007), a imunomarcação positiva dos hemangiossarcomas caninos para o fator de von Willebrand foi de $73 \%, 89 \%$ e $100 \%$, respectivamente. 0 fator de von Willebrand é uma proteína presente no interior dos corpúsculos de Weibel-Palade, organelas citoplasmáticas de células endoteliais. Essa proteína também está presente no citoplasma de megacariócitos. Nestes 40 casos aqui descritos, todos foram positivos para o fator de von Willebrand, sempre em um padrão granular e com intensidade variável, entretanto, mesmo naqueles casos fracamente positivos, a imunomarcação das células neoplásicas era facilmente visualizada, à semelhança do que já havia sido descrito em um estudo prévio que utilizou esse marcador em casos de tumores vasculares vesicais de bovinos (Gabriel 2008).
Os três casos de hemangiossarcoma com padrão epitelioide marcaram fortemente, semelhantemente ao que foi observado por outros autores (Warren \& Summers 2007) e isso parece ser uma característica destes neoplasmas, pois, semelhantemente ao que foi observado neste estudo, não houve correlação entre o grau de diferenciação das células neoplásicas epitelioides e a imunomarcação citoplasmática para o fator de von Willebrand (Weiss \& Enzinger 1982). Esse achado é importante, pois confirma a possibilidade da utilização desse marcador em caso de dúvida quanto à origem celular frente a um neoplasma epitelioide com padrão não obviamente vascular.

A partir da imuno-histoquímica foi possível observar que não há correlação linear positiva entre intensidade de imunomarcação e diferenciação celular, grau de mitoses ou pleomorfismo, visto ter sido muito mais comum a ocorrência de casos bem diferenciados (84\%) e com marcação leve ou moderada $(91,7 \%)$ ou de casos pouco diferenciados $(16 \%)$ e com marcação forte $(8,3 \%)$ do que o contrário. Esse resultado é totalmente diferente daquele encontrado por outros autores (Sabattini \& Bettini 2009), que justificam seus achados no fato de que ao se tornarem menos diferenciadas, as células endoteliais neoplásicas passam a ter menos corpúsculos de Weibel-Palade, e, assim, perdem a imunomarcação para o fator de von Willebrand (Cerelli \& Wick, 2006). Em nossa opinião, aqueles casos em que as células eram menos diferenciadas não necessariamente demonstravam marcação mais forte, mas a presença de células marcadamente atípicas, muitas das quais tinham citoplasma abundante para serem interpretadas como endoteliais com base apenas na morfologia, tornavam mais fácil a visualização dos grânulos.

\section{CONCLUSÕES}

A partir dos achados encontrados nestes 40 casos de hemangiossarcoma em cães podemos concluir que:

- independentemente do sítio anatômico inicial, os órgãos mais afetados incluem: baço, pulmão, fígado, peritônio, rim, encéfalo, pleura e coração;

- a apresentação macroscópica mais comum são os tumores, que ocorrem principalmente como nódulos ou massas, variavelmente vermelhos e macios;

- além da presença dos tumores, outros achados de necropsia incluem principalmente hemoperitônio e, consequentemente, anemia;

- dentre os critérios microscópicos mais comumente avaliados na rotina do diagnóstico anatomopatológico (grau de diferenciação, índice mitótico, padrão estromal, pleomorfismo celular, atipia, necrose, hemorragia e trombose) nenhum demonstrou qualquer relação com o grau de agressividade;

- com certa frequência ocorrem áreas de proliferação vascular benigna (angiomatose) e de hematopoiese extramedular intraneoplásicas;

- a imuno-histoquímica utilizando anticorpo anti-fator de von Willebrand é invariavelmente positiva e auxilia inclusive no diagnóstico definitivo daqueles casos menos diferenciados; e

- cães idosos e da raça Pastor Alemão possuem risco 
aumentado para o desenvolvimento dessa forma de câncer.

Com base nas combinações de órgãos afetados e a fim de evitar divergências entre patologistas, recomendamos que os tumores sejam separados em: solitário, primário com metástase(s) e multicêntrico. Nesse ponto, lembramos que solitário é aquele caso em que há apenas um órgão afetado, multicêntrico é aquele caso em que vários órgãos são acometidos sem que seja plausível estabelecer um sítio anatômico inicial e primário com metástase(s) são aqueles casos que preenchem um dos quatro critérios discutidos neste artigo.

Agradecimentos.- Mariana Martins Flores é bolsista do Conselho Nacional de Desenvolvimento Científico e Tecnológico (CNPq).

\section{REFERÊNCIAS}

Bertazzolo W., Dell'Orco M., Bonfanti U., Ghisleni G., Caniatti M., Masserdotti C., Antoniazzi E., Crippa L. \& Roccabianca P. 2005. Canine angiosarcoma: cytologic, histologic, and immunohistochemical correlations. Vet. Clin. Pathol. 34(1):28-34.

Brown O., Patnaik A.K. \& MacEwen G. 1985. Canine hemangiosarcoma: retrospective analysis of 104 cases. J. Am. Vet. Med. Assoc. 186(1):56-58.

Cerelli L.A. \& Wick M.R. 2006. Immunohistology of soft tissue and osseous neoplasms, p.65-120. In: Dabbs D.J. (Ed.), Diagnostic Immunohistochemistry. Elsevier, Pittsburgh.

Culbertson M.R. 1982. Hemangiosarcoma of the canine skin and tongue. Vet. Pathol. 19(5):556-558

Cullen J.M., Page R. \& Misdorp W. 2002. An overview of cancer pathogenesis, diagnosis and management, p.3-44. In: Meuten D.J. (Ed.), Tumours in Domestic Animals. $4^{\text {th }}$ ed. Iowa State Press, Ames.

Ferrer L., Fondevila D., Rabanal R.M. \& Vilafranca M. 1995. Immunohistochemical detection of CD31 antigen in normal and neoplastic canine endothelial cells. J. Comp. Pathol. 112(4):319-326.

Fighera R.A. 2008. Causas de morte e razões para eutanásia de cães. Tese de Doutorado em Medicina Veterinária, Curso de Pós-Graduação em Medicina Veterinária, Universidade Federal de Santa Maria, Santa Maria, RS, 172p.

Fighera R.A., Souza T.M., Silva M.C., Brum J.S., Graça D.L., Kommers G.D., Irigoyen L.F. \& Barros C.S.L. 2008. Causas de morte e razões para eutanásia de cães da Mesorregião do Centro Ocidental Rio-Grandense (19652004). Pesq. Vet. Bras. 28:223-230.

Gabriel A.L. 2008. Aspectos epidemiológicos, clínicos e lesões vesicais na intoxicação crônica espontânea por Pteridium aquilinum em bovinos. Dissertação de Mestrado em Medicina Veterinária, Curso de Pós-Graduação em Medicina Veterinária, Universidade Federal de Santa Maria, Santa Maria, RS. 92p.

Goldschmidt M.H. \& Hendrick M.J. 2002. Tumors of skin and soft tissues, p.45-118. In: Meuten D.J. (Ed.), Tumours in Domestic Animals. $4^{\text {th }}$ ed. Iowa State Press, Ames.

Gross T.L, Ihrke P.J., Walder E.J. \& Affolter V.K. 2009. Doenças de pele do cão e do gato. $2^{\text {nd }}$ ed. Roca, São Paulo, p.733-738.
Hayden D.W., Bartges J.W., Bell F.W. \& Klausner J.S. 1992. Prostatic hemangiosarcoma in a dog: clinical and pathologic findings. J. Vet. Diag. Invest. 4:209-211.

Hargis A.M., Ihrke P.J., Spangler W.L. \& Stannard A.A. 1992. A retrospective clinicopathologic study of 212 dogs with cutaneous hemangiomas and hemangiosarcomas. Vet. Pathol. 29(4):316-328.

Hendrick M.J., Mahaffey E.A., Moore F.M., Vos J.H. \& Walder E.J. 1998. Histological classification of mesenchymal tumors of skin and soft tissues of domestic animals. Armed Forces Institute of Pathology, Washington, DC

Hirsch V.M., Jacobsen J. \& Mills J.H.L. 1981. A retrospective study of canine hemangiosarcoma and its association with acanthocytosis. Can. Vet. J. 22(5):152-155.

Johns J.L. \& Christopher M.M. 2012. Extramedullary hematopoiesis: a new look at the underlying stem cell niche, theories of development, and occurrence in animals. Vet. Pathol. 49(3):508-523.

Kleine L.J., Zook B.C. \& Munson T.O. 1970. Primary cardiac hemangiosarcomas in dogs. J. Am. Vet. Med. Assoc. 157(3):326-337.

Meuten D.J. 2002. Tumours in Domestic Animals. $4^{\text {th }}$ ed. Iowa State Press, Ames.

Monluxa W., Anderson W.A. \& Davis C.L. 1956. A survey of tumors occurring in cattle, sheep and swine. Am. J. Vet. Res. 17:649-677.

Pirie C.G., Knollinger A.M., Thomas C.B. \& Dubielzig R.R. 2006. Canine conjunctival hemangioma and hemangiosarcoma: a retrospective evaluation of 108 cases (1989-2004). Vet. Ophthalmol. 9(4):215-226.

Sabattini S. \& Bettini G. 2009. An immunohistochemical analysis of canine hemangioma and hemangiosarcoma. J. Comp. Pathol. 140(2-3):158168.

Schultheiss P.C. 2004. A retrospective study of visceral and nonvisceral hemangiosarcoma and hemangiomas in domestic animals. J. Vet. Diag. Invest. 16(6):522-526.

Southwood L., Shott H.C., Henry C.J., Kennedy F.A., Hines M.T., Geor R.J. \& Hassel D.M. 2000. Disseminated hemangiosarcoma in the horse: 35 cases. J. Vet. Intern. Med. 14:105-109.

Souza T.M., Fighera R.A., Irigoyen L.F. \& Barros C.S.L. 2006. Estudo retrospectivo de 761 tumores cutâneos em cães. Ciência Rural 36:555-560.

Tamburini B.A., Trapp S., Phang T.L., Schappa J.T., Hunter L.E. \& Modiano J.F. 2009. Gene expression profiles of sporadic canine hemangiosarcoma are uniquely associated with breed. Plos One 4:5549.

Von Beust B.R., Suter M.M. \& Summers B.A. 1988. Factor VIII-related antigen in canine endothelial neoplasms: an immunohistochemical study. Vet. Pathol. 25(4):251-255.

Ward H., Fox L.E., Calderwood-Mays M.B., Cammer A.S. \& Couto C.G. 1994. Cutaneous hemangiosarcoma in 25 dogs: A retrospective study. J. Vet. Intern. Med. 8:345-348.

Warren A.L. \& Summers B.A. 2007. Epithelioid variant of hemangioma and hemangiosarcoma in the dog, horse and cow. Vet. Pathol. 44(1):15-24.

Weiss E. 1974. Tumours of the soft (mesenchymal) tissues. Bull. World Health Organ. 50(1/2):101-110.

Weiss S.W. \& Enzinger F.M. 1982. Epithelioid hemangioendothelioma. Am. Cancer Soc. 50:970-981. 